up of fragments from the surrounding gneiss. The stones in this deposit are for the most part perfectly angular, and are sometimes stuck on end in the mass. They underwent but little re-arrangement after they were thrown down, though occasional lenticular seams of red sandstone running through the rock serve to prove that it is lying as a flat cake on the gneiss. My friend $\mathrm{Mr}$. Norman Lockyer accompanied me in the examination of this hill. We searched long for a striated stone among the component materials of the breccia, but the matrix was too firm to allow us to bare and extract any of the pebbles or boulders. We traced, however, the characteristic rounded bossy surface of the gneiss until it passed under the breccia, and were convinced that, could the outlier of breccia be stripped off, the same kind of surface would be found below it as on the gneiss above and around. The valley in which this little fragment of a once more extensive deposit of breccia lies certainly existed as a hollow in
Cambrian times. From the narrowness of its present outlet, which has been cut by the escaping streamlet, and from the nature of the breccia, we may infer with some plausibility that the hollow was filled with water, and may have been a lake. It was almost certainly a rock-basin, surrounded with hills of gneiss that had been worn into undulating dome-shaped hummocks.

Behind the new hotel at Gairloch the ground rises steeply into a rocky declivity of the old gneiss. Along the base of these slopes the gneiss (which is here a greenish schist) is wrapped round with a breccia of remarkable coarseness and toughness. We noticed some blocks in it fully five feet long. It is entirely made up of angular fragments of the schist underneath, to which it adheres with great tenacity. Here again rounded and smoothed domes of the older rock can be traced passing under the breccia, as at $a$ in Fig. 4. On the coast immediately to the south of the new Free Church a series of
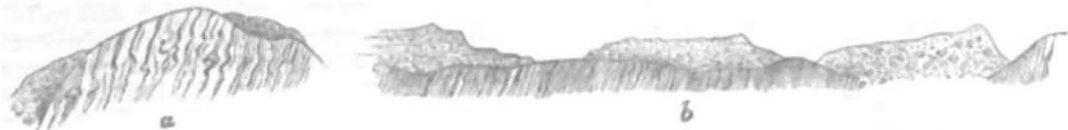

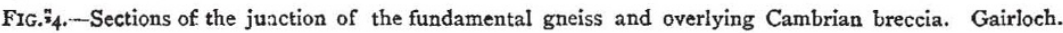

instructive sections again lays bare the worn undulating platform of gneiss, with its overlying cover of coarse angular breccia (b in Fig. 4).

On these far northern shores, then, there still remain fragments of the surface on which our oldest sedimentary accumulations were deposited. These fragments are found to bear in their smoothed hummocky contours a striking resemblance to the surface which geologists now always associate with the action of glacier-ice. There can at least be no doubt that they are denuded surfaces. The edges of the vertical and twisted beds of gneiss and schist have been smoothly bevelled off. These rocks, however, would never have assumed such a contour if exposed merely to ordinary sub-aërial disintegration. They would have taken sharp craggy outlines like those which are here and there gradually replacing the ice-worn curves of the roches moutonnées. They have certainly been ground by an agent that has produced results which, if they were found in a recent formation, would, without hesitation, be ascribed to land-ice. The breccia, too, is quite comparable to moraine-stuff. Without wishing at present to prejudge a question on which I hope yet to obtain further evidence, I think we have in the meantime grounds for concluding that in the northwest of Scotland there is still traceable a fragment of the earliest known land-surface of Europe, that this primeval country had a smooth undulating aspect not unlike that of the west of Sutherland at the present time, that it contained rock-hollows, some of them filled with water, that into these hollows piles of coarse angular detritus were thrust, that around and beneath the tracks where this detritus accumulated the gneiss was worn into domeshaped forms strongly suggestive of the operation of land-ice, and that though the ice of the last Glacial Period undoubtedly ground down the platform of gneiss, bared as it was of the overlying formations, it found a surface already worn into approximately the same forms as those which it presents to-day. ARCH. GEIKIE

\section{EXCRETION OF WATER BY LEAVES ${ }^{1}$}

IN the pamphlet referred to below Dr. Moll gives a detailed account of his investigations upon the excretion of drops of water by leaves, of which an outline was given in the Botanische Zeitung for January 23 of the present year.

The question with which he more especially deals is as to whether this excretion is a function which is performed by all leaves, or whether it is confined to such leaves only as possess specially modified organs. The method which he employed in his researches is to place the leaves under the most favourable condition for the excretion of drops by diminishing as far as possible their transpiration, and by supplying them with water. Under ordinary circumstances the excretion of drops is due to the action of the root-pressure; but Dr. Moll substitutes for this, in his experiments, the pressure of a column of mercury, in order to have this important factor in the problem completely under control.

The results, which are of considerable interest, may be briefly stated as follows : out of sixty plants experimented on, the leaves of twenty-nine excreted drops without becoming injected, that is, without their intercellular spaces becoming filled with water; thirteen leaves became injected and excreted drops, and eighteen became injected but did not excrete at all. It appears that the age of the leaf has a very evident influence upon the excretion of drops, for whereas the young leaves of a plant, such as Sambucus nigra or Platanus occidentalis, for instance, readily excrete drops without becoming injected, the older leaves of the

x " Untersuchungen über Tropfenausscheidung und Injection bei Blättern," ron Dr. J. W. Moll. (Amsterdam, 1880.) same plant become injected and excrete scarcely at all. Under these circumstances it is quite possible and even probable, as Dr. Moll himself suggests, that of the eighteen plants the leaves of which became only injected, some at least were capable of excretion at an earlier period. It is only definitely stated of Hedera, Syringa, and Taxus that their leaves do not excrete at all.

As to the organs of excretion, it is effected in eight out of the forty-two cases by means of water-pores, but in four of these cases it is effected also by ordinary stomata; in eight other cases it was found to be effected by stomata, and in three cases it took place at portions of the surface which possessed neither waterpores nor stomata. These last cases are carefully distinguished by Dr. Moll from those in which an excretion took place over the whole surface of the leaf in consequence of exces ive pressure.

From these observations it appears that most leaves, at least so long as they are comparatively young, are capable of excreting water in drops when it is supplied to them in excess, and further, that this excretion is effected by certain organs (Emissarien the author calls them) which may be water-pores, or ordinary stomata, or limited areas of the surface which are histologically undifferentiated. The effect of this excretion is to prevent the injection of the leaves when the root-pressure is great, a condition which would obviously interfere with the circulation of air in the intercellular spaces, and therefore with the function of the leaf. Dr. Moll suggests that possibly some definite correlation exists between the presence of excretory organs and the existence of root-pressure in a plant; for instance, according to Hofmeister ("Flora," 1862), no root-pressure can be detected in Conifers, 
and the author has failed to find any excretory organs in their leaves. It may be added, in conclusion, that these organs can excrete not only water but solutions of substances such as tannin, and the juice of Phytolacca berries. Further, Dr. Moll's observations tend to confirm the view that the woor is the channel by which water is conveyed to the leaves from the roots.

\section{SOCIETIES ANL' ACADEMIES LONDON}

Royal Society, Jane 17.- "On the Constants of the Cup Anemometer," by the Rev, "T. R. Robinson, D.D., F.R.S., \&ec, In a previous paper the author detailed experiments made by attaching ancmometers to a whirling machine, and the conclu. sions to which they led. He was however donbtful of the accuracy of the method; and proposed one depending on the action of natural wind. He has tried this, and he thinks saccess. fully. Two instruments of the Kew type, differing only in friction, were established 22 feet asander on the roof of the house and 16 feet above it: the number of turns made by each, and the time, were recorded by a chronograph, and from these, $v$ and 2', the velocity in miles per hour of the centres of the cups was known.

The friction of one of these (K) was constant; that of the other (E) was varied by applying to a disk on its axle Prony's brake, which was connected with a spring balance whose tension was recorled during the time of experiment hy a pencil moved by clockwork. Thus the mean friction was obtained. It ranged from 353 grains to 4,982 .

'The equation of an anemometer's motion is

$$
V^{2}+v^{2}-2 V v x-\frac{f}{a}=0
$$

where $\mathrm{V}$ is the unknown velocity of the wind, a and $x$ two constants which are to be determined. Each observation gives two cyuations in which there are four unknown yuantities, for it is found that the value of $\mathrm{V}$ changes from one instrument to another. This is partly owing to eddies caused by the buildings, but also in great measure to irregularity of the wind itself. It is however also found that these wind-differences are as likcly to bave + as - signs, and therefore it may be expected that their sum will vanish in a large number of observations. The ordinary methods of elimination fail here even to determine with precision a single constant, and he has proceeded by approximation.

Assuming the value of $a$ given by the actual mescurements in his paper $=15^{\circ} 315$ at $30^{\prime \prime}$ and $32^{\circ}$ for 9 -inch cups, and that there is no resistance as $v^{2}$ except that in the equation, and assuming an approximate value for $x$, we can compute $\mathrm{V}$ and $\mathrm{V}$ '. 'The difference between these must be due to an error in $x$ and to $w$ the wind error, and taking the sum of a series we have

$$
\mathrm{S}\left(\mathrm{V}^{\prime}-\mathrm{V}\right)+\mathrm{S} w-\Delta x \times \mathrm{S}\left(e-e^{\prime}\right) ; e \text { being }-\frac{\mathrm{V}}{\sqrt{x^{2}-1+\frac{t^{\prime}}{\alpha v^{\prime 2}}} .}
$$

If the obscrvations are sufficiently numerous $\mathrm{S} z v=0$, with the assumed $x+\Delta x$ thus found, recompute the $V$ till the sum of $\mathrm{V}^{\prime}-\mathrm{V}$ is insensible, and the final $x$ will give $\mathrm{V}$ with a high degree of probability. Twenty-one observations gave a value of $x$ considerably larger than what was obtained with the whirling machine, and of course the limiting factor (that when $v^{\prime}$ is so large that $\frac{f^{\prime}}{\alpha i^{\prime}}$ may be neglected). It is for the Kew type $q^{\prime \prime}$ cups 24 " arms 2,831. In this series the differences are so evidently casual as to show that neither $\alpha$ or $x$ change with $v$.

Witt this $x, \mathrm{~K}$ gives the true value of $\mathrm{V}$ at it; therefore if any other type be sulstituted for $\mathrm{E}^{\prime}$ it is easy to find its $x$, for its $\alpha$ is as area of cups, its $f^{\prime}$ is known, ancl assuming its $x^{\prime}$ and computing as before, we get similarly its $\Delta x$. He tried five different types and obtained very unexpected results, for he found that the $x$ varied as some inverse function of the diameter of the cups and of the hrms. Ile gives its values.

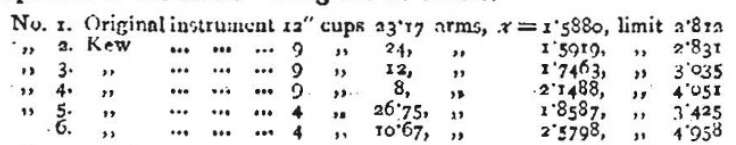

No. 6 is similar to No. 2, and it might be expected that their constants would be cqual. The cause of these differences is partly the eddies caused by the cups being more powerful when the arms are short, but still more the presence of high powers of the arm and diameter occurring in the expressions of the mean pressures on the concave and convex surfaces of the hemispheres. In the present state of hydrodynamics we cannot assign these expressions, but we know enough to see that such powers may be present.

As each type of anemometer has its own constants, the author would suggest to meteorologists the propriety of confining themselves to one or two forms. For fixed instruments he considers the Kew one as good as any, and would wish to see it generally adopted. For portable ones he has no experienoe except: with Casella's $3^{\prime \prime}$ cups $6^{\prime \prime}$ arms, which he found very convenient ; he has not however leterwined its constants. Some selection of the sort seems necessary if it is wished to have an uniform system of wind-mcasures.

Entomological Society, August 4-J. W. Dunning, M.A., F.L.S., vice-president, in the chair.-Sir Sidney Saunders forwarded for exhibition four living specimens of Prosopis rubicola, all stylopised females recently bred from larvo. extracted from briars received from Epirus, and contributed notes thereon,Mis; E. A. Ormerod exhibited a soft gall-like formation found on Rhododendron forrugineum, but believed to be of fungoid growth.-Mr. Billups exhibited a specimen of Ileptaulacus villosus from Box Hill.-Mr. H. J. Elwes communicated a pajer on the genus Colias.-Mr. W. I., Distant read a paper entitled "Notes on Exotic Rhynchota," with descriptions of new species.

\section{VIENNA}

Imperial Academy of Sciences, July 8.-The theory of the galvanic element, by Prof. Fxner.-Contributions to a knowledge of the eruptive rocks of the neighbourhood of Schemnitz, by Dr. Hussak.-Action of ammonia on isatir (third part), by Ijr. Sommaragua.-On a new hydrocarbon of the camphor group, by IIerr Kaehler and 1)r. Spitzer.-On china-acid, by Dr. Skraup. - On the influence of concentration of the liquids on the electromotive force of the Daniell element, by Dr. flepperger.-On the action of linear current variations on nerves, by Prof. Fleischl.

July 15.-River-fishes of South America, and other ichthyo. logical contributions, by Dr. Steindachncr, - Researches on the influence of light on formation of chlorophyll, with intermittent illumination, by Urs. Mikosch and Stïhr.-On the decompo. sition of simple organic combinations by zinc powder (continued), by $\mathrm{Dr}$. Jahn, $-\Lambda$ ction of mercury-ethyl on iodides of hydrocarbons, and a new synthesis of acetylene, by Dr. Suida.-On the compounds formed in action of ammonia and water on some chinon-like derivatives of naphtol, by Prof. Ludwig and I)r. Manthner.-Iron oxalate and some of its duuble salts, by IIerr Valenta.-On the decomposition of iron chloride and some organic ferricl salts in light, liy 1)r. Eder.-On the phenomena in Geissler tubes under external action (second part), by Prof. Reitlinger and Dr. Urbanitzky.-On the isomorphism of rhomholedric carbonate and nitrate of sodium, by Herr 'lschermak. - Measurements of crystals of tellurium-silver, by I)r. Becke.On the behnviour of some resins in distillation over pinc powder, by Herr Bötsch.-On saligenin derivatives, by the same.-On compounds of the pyrrol series, by Dr. Ciamician.

\section{CONTEN'TS}

PAGR

DR. BASTIAN ON THF. BR,IN

IATTTEKS TO TIIE EDITOR:

Enzoic and Palzozuic.-Principal J. W. LAwson, F.R.S. . . . 38

Alga.-G. F. Chavtpri

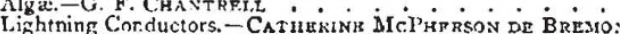

Strange Methud of Crussing a Torrent. $-F$. F. T UCKETr.

Fascination.--Rrenakin foncsoy.

"Hascination.--RICHAKI?

IHe Britisn Ascocin in

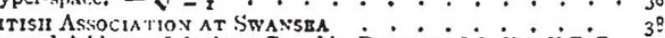

Inaugural Address of Andrew Crombic Ramsay, LI.i.: F.R.S., V.P.f...., Director-General of the Geological Survey of the United Kinglum, and of the Museum of Practical Geology,

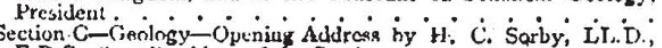

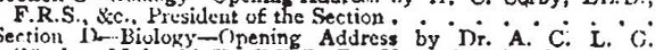

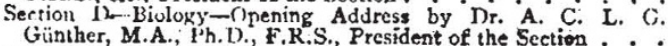
Notes......... Seetion * 393

OUR Astronomicai ĆOLUm:-

The Siatellites of Saturn

The Binary-Star a Centauri

The Creat Comet of 1880

F.R.S.MENT of Primeral EuRope. By Prof. Arair. Grikie, ExCRETION OF WATBR HY Leaves. By Dr. J. W. Moi.t : : * 400

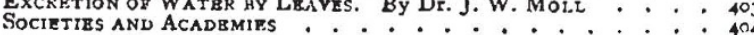

